\title{
Emergence and optimization of upright posture among hominiform hominoids and the evolutionary pathophysiology of back pain
}

\author{
Aaron G. Filler, M.D., Ph.D., F.R.C.S. \\ Institute for Spinal Disorders, Cedars-Sinai Medical Center, Los Angeles; Center for Advanced Spinal \\ Neurosurgery, Santa Monica, California; and Museum of Comparative Zoology, Harvard University, \\ Cambridge, Massachusetts
}

\begin{abstract}
$\checkmark$ The lordotic region of the lumbar spine is a significant focus of pain and dysfunction in the human body, and its susceptibility to disorders may reflect its substantial reconfiguration during the course of human evolution. The basic anatomy of the lumbar vertebra in Old World Monkeys and Early Miocene apes, or proconsulids, retains typical mammalian architecture. The lumbar vertebra in humans is different in the repositioning of the lumbar transverse process dorsal to the vertebral body rather than originating on the body itself and in the loss of the styloid process that is adjacent to the facets in other primates. These two features appeared in Morotopithecus bishopi 21.6 million years ago, suggesting that this ape is the founder of an upright hominiform lineage. The iliocostalis lumborum muscles migrated onto the iliac crest approximately 18 million years ago, becoming a powerful lateral flexor muscle of the trunk. The posterior superior iliac spine shifted far dorsal to the longissimus insertion in the genus Homo between 1 and 2 million years ago, making this muscle a powerful extensor of the lumbar spine. Functionally, the establishment of strong muscular flexors and extensors adds dynamic compressive stresses to the lumbar disks and also makes these muscles susceptible to strain.
\end{abstract}

(DOI: 10.3171/FOC-07/07/E4)

\begin{abstract}
KEY WoRdS - back pain • evolution • hominoid - iliocostalis lumborum muscle • lumbar transverse process
\end{abstract}

$\mathrm{P}$ AINFUL DYSFUNCTION of the human spine has an extraordinarily high incidence both from the point of view of point prevalence and lifetime incidence. ${ }^{1}$ In fact, it is extraordinary to identify an individual older than 45 years of age who has never had a significant or severe episode of back pain at least once in his or her adult life. It is difficult to determine whether other animal species share this frequency and severity of spinal pain. However, the concentration of spinal abnormalities at points of reversed spinal curvature in the human spine is striking. Of the 24 intervertebral joints, it is C5-6, C6-7, C4-5, L4-5, and L5-S1 $1^{3,12,19,20}$ (20\% of the total) that are associated with the highest incidence of pathophysiology, and these are the segments most involved in the lumbar and cervical lordoses.

In comparison with functional spinal anatomy in other mammals, it is immediately apparent that the lordotic curvatures of the cervical and lumbar spine are unique as-

Abbreviation used in this paper: PSIS = posterior superior iliac spine. pects of the human body plan necessitated by our upright posture. The coincidence between the highest rates of mechanical dysfunction and the areas of most extensive anatomical transformation suggests a relationship between the locations of greatest anatomical transformation and those of the most common musculoskeletal failures.

Although one generally appreciates that the global architecture of the human spine is different from that of other mammals, the specific anatomical differences have never been well described, in part because the anatomy of the human spine is so profoundly different from that of other mammalian species that any detailed comparisons have been challenging. Moreover, in the past 20 years we have made enormous advances in our understanding of human spinal mechanics that have never been considered in the light of evolutionary data. Finally, a series of discoveries of spinal fossils from various human antecedents have only recently made it possible to assemble a valid time-based sequence of events of the origin of human spinal anatomy.

In this paper I will consider the sequence of events leading to the emergence of the modern human spine from the 


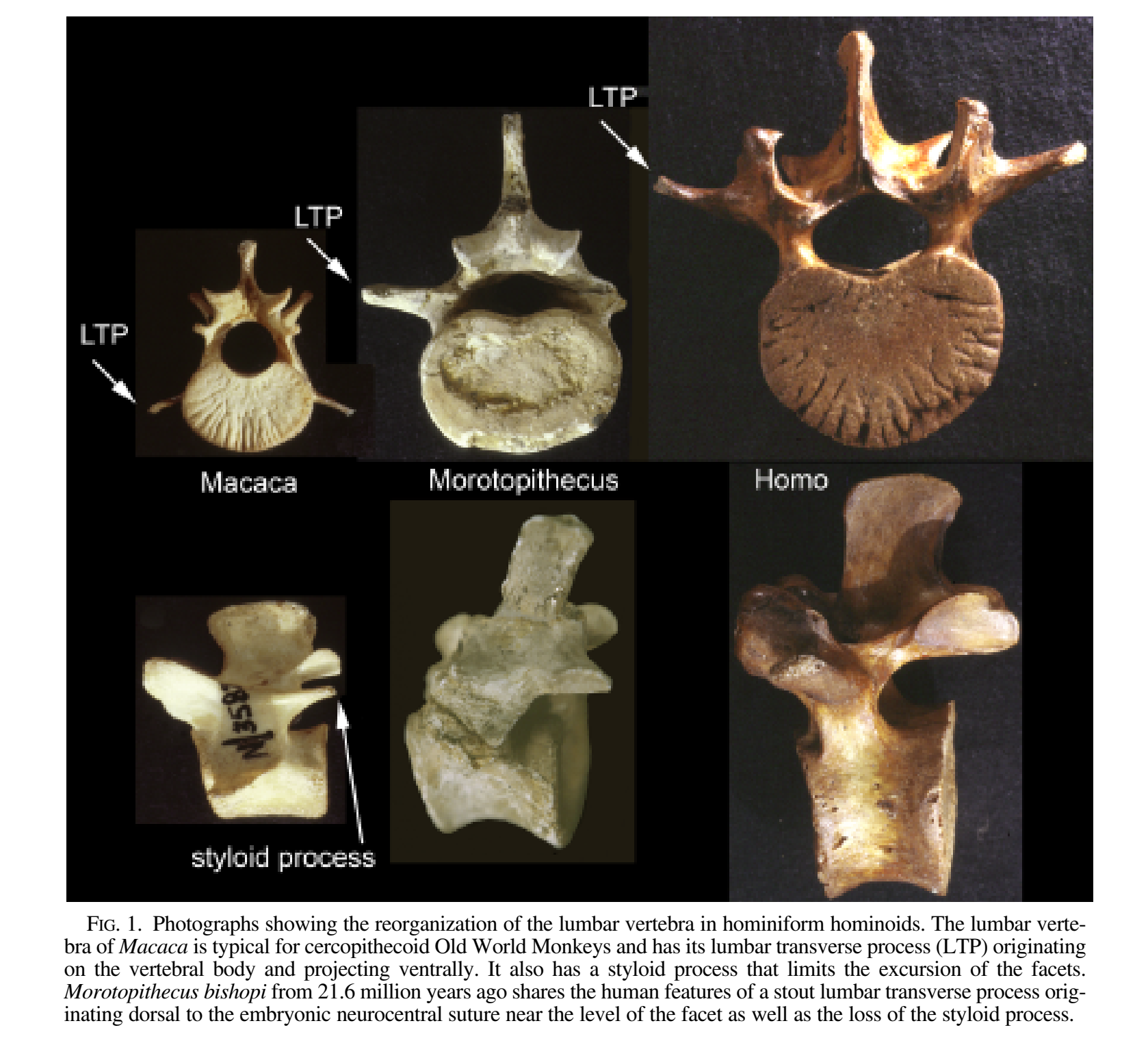

standard mammalian spine and identify aspects of the involved changes that may have particular relevance to the high prevalence of dysfunction in the lumbar spine in modern humans.

\section{Materials and Methods}

Dissection of the muscular anatomy in the lumbar spine of five gibbons, five chimpanzees, and five macaque monkeys was performed in collections at the Museum of Comparative Zoology and the Peabody Museum of Harvard University, the Smithsonian Institution, and the Department of Anthropology at the University of Chicago. Osteological evaluation of lumbar spine material from 250 mammalian species, living and extinct, from across a period of 220 million years and including various human antecedents, was conducted using materials from the $\mathrm{Mu}-$ seum of Comparative Zoology, Cambridge, Massachusetts; The American Museum of Natural History, New York, New York; The Field Museum of Natural History,
Chicago, Illinois; the Smithsonian Institution, Washington, DC; and the Cleveland Museum of Natural History, Cleveland, Ohio (Todd Collection and fossils from Australopithecus afarensis ["Lucy"]).

\section{Results}

The modern human spine reflects three major phases of transformation relative to the more general mammalian spinal anatomy of related primates. The most dramatic alteration is an apparently abrupt event occurring approximately 21 million years ago in which the lumbar transverse processes moved from an ancestral position on the midvertebral body to a novel location on the arch, posterior to the pedicle. This transformation reversed the mechanical function of the lumbar intertransverse ligaments and converted the longissimus muscles into major lateral flexor and extensor muscles of the spine (Fig. 1).

A second phase involved the reorientation of the iliocostalis lumborum muscles from a function as direct seg- 


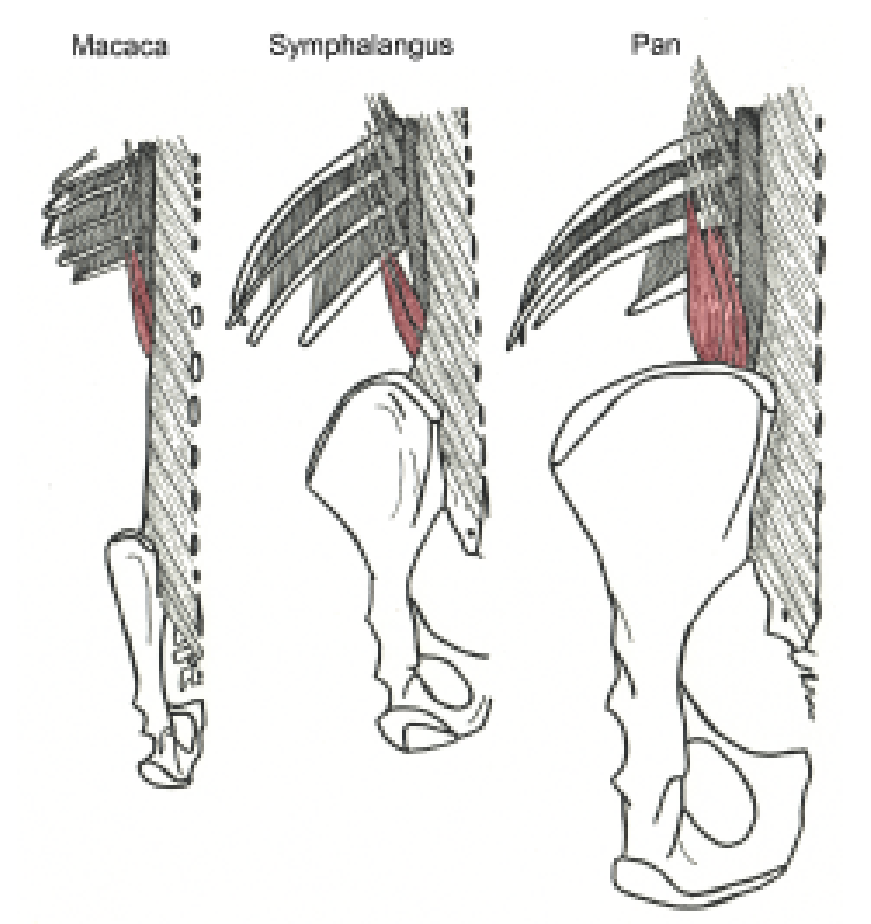

FIG. 2. Drawings depicting the reorganization of the iliocostalis lumborum muscle in the great apes and humans. In most mammals this muscle (red area) is a segmental one originating on the epaxial fascia. This arrangement is present in Old World Monkeys such as Macaca and in the small Southeast Asian apes such as the gibbon (Hylobates) and siamang (Symphalangus). In chimpanzees (Pan), gorillas, orangutans, and humans, the iliocostalis lumborum muscle has moved out onto the iliac crest and is greatly expanded in volume so that it is a strong lateral flexor muscle of the lumbar spine and torso.

mental actors inserting at each spinal level to lumbar global actors reaching across the lumbar spine from an origin on the iliac crest (Fig. 2). This phase appears to have taken place approximately 15-18 million years ago.

The third phase occurred within the last 1-2 million years and is based on a repositioning of the PSIS to a new location well posterior to the spine. This repositioning greatly increased the mechanical advantage of the lumbar musculature in effecting lumbar extension and appears to be related to the appearance of lumbar lordosis (Fig. 3).

\section{Embryological and Anatomical Bases for Lumbar Mechanical Reversal}

In a pronograde or horizontal body posture during locomotion, the lumbar spine must resist the tendency of gravity to produce lumbar hyperextension. Optimally, this support function should be passive; that is, it should not require ongoing muscular contraction and thus become subject to fatigue. Various groups of modern mammals use two very different architectural mechanisms for this function. In ungulate species such as the antelope (Artiodactyla), horse (Perissodactyla), and elephant (Paenungulata), this mechanism involves complex and elaborate surface interlocks of facet joints. In this architecture, the facets come under weight-bearing compression as the spine begins to pass into extension, and a rigid block against ex- tension is achieved. This type of functional system appears to have evolved independently in parallel several times. $^{2}$

In a variety of other mammalian groups, the support relies on the lumbar transverse processes, which typically project anterior (ventral) to the intervertebral axis of rotation. ${ }^{2}$ As the spine passes into extension, the lumbar transverse processes begin to separate from each other until the heavy elastic intertransverse ligaments become taught and prevent further extension. This functional complex also appears to have evolved independently in parallel several times. It is seen in many marsupials such as the kangaroo (Marsupialia, Diprotodonta) and carnivores (Carnivora) as well as in most rodents and primates.

Virtually all mammalian species that use ventrally placed lumbar transverse processes to resist extension also have prominent styloid processes directed posteriorly, just lateral and ventral to the facet joint, that are the point of insertion for the longissimus lumborum muscles. The result of the styloid position just at the base of the inferior articular process is the provision of a secondary osseous block to hyperextension; the superior facet can advance relative to the inferior facet of the preceding vertebra only until it reaches the base of the styloid process.

IN THE HUMAN LUMBAR PATTERN, all three of these mechanisms for limiting extension have been lost, with the following consequences: 1) There is no primary facet-based block to extension. 2) The transverse processes are dorsal to all functional locations of the center of the axis of rotation for extension and so move toward each other during this motion. 3) There are no styloid processes. Together, these three alterations in typical mammalian lumbar functional architecture constitute the basis for the unique postural role of the lumbar spine in humans.

All three of these features are present in the lumbar vertebra of Morotopithecus bishopi from 21.6 million $^{2,8,9,16,17}$ years ago as well as in the later Miocene upright apes Oreopithecus bambolii ${ }^{7,13}$ and Pieralopithecus catalaunicus. ${ }^{10}$ The occurrence of this set of features is most remarkable because of the timing in Morotopithecus. The split between the ancestors of the Old World Monkeys (cercopithecoids) and the ancestors of apes and humans (hominoids) took place approximately 23 million years ago. ${ }^{15}$ Once that split occurred, a period in which a considerable variety of early ape species emerged appears to follow. ${ }^{5,11}$ These early apes can be placed in the proconsulid family. Notably, their lumbar vertebrae resemble those in monkeys; they have the lumbar transverse process on the vertebral body rather than the arch, and they have styloid processes. ${ }^{18}$

Morotopithecus bishopi therefore emerges from among the various proconsulid hominoids as a representative of a new subgroup that can be called the "hominiforms." The key difference between proconsulid and hominiform apes of the East African Early Miocene is that the hominiforms have the same basic lumbar spine anatomy as that in modern humans (Fig. 1).

This modified vertebral pattern is quite unusual for a mammal and appears to have emerged fairly abruptly in a limited period of time. From that point of view, it is almost possible to view this modification as a birth defect, mak- 


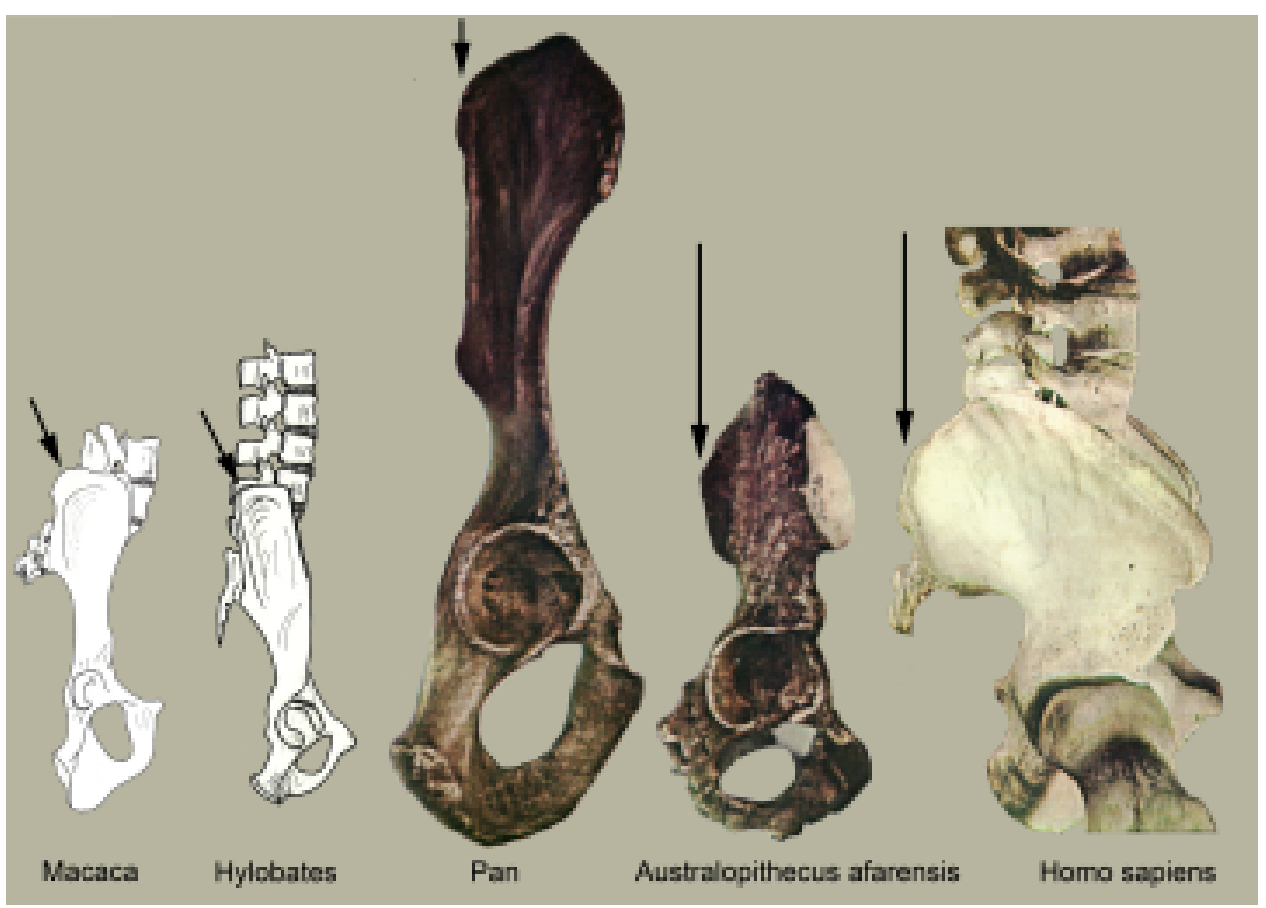

FIG. 3. Drawings and photographs revealing the repositioning of the PSIS in the genus Homo. The standard position of the PSIS (arrows) is near the level of the styloid processes or lumbar transverse processes in monkeys (Macaca) and apes such as the gibbon (Hylobates) and chimpanzee (Pan). This is still the case in the early hominine Australopithecus afarensis from 3.5 million years ago. In the genus Homo, however, this point of origin for the longissimus lumborum muscles is moved far dorsal to the lumbar vertebral column, thus greatly increasing leverage for extension.

ing the spine essentially incompetent for routine quadrupedal locomotion. The lack of any intrinsic mechanism to resist extension under the force of gravity in a horizontal pronograde position allowed the lumbar spines of these apes to function well only in upright or orthograde postures. The large modern hominiform apes such as gorillas and orangutans have independently evolved new types of osseous ridges that lock the lumbar facets against extension. ${ }^{2}$ This finding suggests a continuous series of upright ancestral apes - with body plans more or less like those in a modern human - from which other apes have descended to establish diagonograde (between upright and horizontal) postures during knuckle walking and other straightarm/flexed-leg gaits. ${ }^{4}$

\section{Muscular Reorganization}

There is a general trend among mammals for the segment-by-segment muscles in many other vertebrates to fuse together and reach across multiple spinal segments. However, the iliocostal muscles that extend from the iliac crest to the ribs and vertebrae tend to be retained as segmental muscles even in the monkeys.

In the great apes and humans, however, the iliocostalis lumborum muscles tend to become fused together and bridge across directly from the iliac crest to the ribs (Fig. 2 ). This configuration appears to provide far greater leverage for lateral bending. This leverage is important both for arm swinging (brachiation) in the trees using overhead suspension during locomotion in typical ape fashion and for walking. The iliocostal muscles of the large hominoids are thus better able to position and balance the upper body over the pelvis during walking, running, and carrying. However, this architecture and use of the iliocostalis lumborum muscle are novel and atypical relative to other mammals and nonmammalian vertebrates and may represent reasons why tears and spasms of the iliocostalis lumborum muscle constitute an extremely common site of musculoligamentous back pain.

This transformation does not occur to the same degree in the small Southeast Asian apes-the gibbons and siamangs - so it probably reflects events that occurred in the hominiform lineage approximately 15 to 18 million years ago. In addition to the role of the iliocostalis lumborum muscle in general balance during locomotion, it is an important optimization for carrying heavy objects with a single arm, which can be important in tasks as widespread as transporting food and carrying infants and young children in a lateral location.

\section{Repositioning of the Posterior Superior Iliac Spine}

The third and final major reorganization of the lumbar anatomy is the posterior repositioning of the PSIS of the pelvis. This change is extremely important because the great bulk of human spinal muscles originate from this region of the iliac crest.

In other hominoids the PSIS remains close to the plane of the lumbar transverse processes. It is often actually ventral to the position of the tips of the lumbar spinous processes (Fig. 3).

This transformation is a feature of the genus Homo because it has progressed to a limited degree only in Australopithecus (Fig. 3). The elaboration of a massively 
expanded PSIS that is rotated far posteriorly greatly increases the potential mass and leverage of the extensor muscles of the spine. The same functional considerations apply here with regard to the reorganization of the iliocostalis lumborum muscle in earlier hominoids. Increased power for these muscles is important for balancing the trunk during bipedal locomotion. Moreover, it greatly increases power and resilience for carrying heavy objects in front of an individual.

\section{Effect of the Muscular Transformations on the Lumbar Disks}

The lateral shift of the iliocostalis lumborum muscle with relocation of its origins to the iliac crest as well as the posterior shift of the PSIS with its longissimus lumborum muscle origin greatly increases leverage for work and locomotion; however, the lumbar disks are thus placed under greater pressure. For instance, when a heavy object is carried in front of the body and the longissimus lumborum muscles pull back to accomplish extension a great increase in the compressive force on each lumbar disk occurs.

From this point of view, it is apparent that the gains in muscle power for lifting and carrying are made at the cost of greatly increased compressive stress on the vertebral disks. Consider that monkeys and diagonograde apes carry their young on their backs or with the infant hanging by their arms from underneath the mother's belly. The weight of the infant tends to pull the spine into extension around a rotational axis at the dorsal edge of the disk, therefore actually stretching the disk rather than compressing it.

The small upright Southeast Asian apes (gibbons and siamangs) typically carry their young in their laps, that is, using a platform of flexed legs while they travel along by arm swinging. Once again, carrying the young during locomotion causes stretching of the lumbar disks and not compression.

In the hominine species-Australopithecus, Homo, and other closely related extinct early humans-who carry their young and other heavy loads in a fully upright and bipedal position, the effects of the loads on the lumbar spine are almost entirely compressive. The muscular action of the iliocostalis lumborum muscle in resisting lateral bending and the longissimus lumborum in resisting forward bending magnify the compressive effects. Even when loads are not carried, the routine activation of these muscles with each step to help balance the torso over the pelvis adds to repetitive compressive stress.

While humans walk, the pelvis undergoes a complex pattern of lateral dips and forward/backward rocking motions. ${ }^{14}$ The muscular system of the trunk acts constantly to counter and dampen the effects of normal pelvic oscillations on the head. This action helps accomplish a smoothly progressing head position during locomotion. One striking aspect of occasional, untrained bipedal walking in chimpanzees is the extremes of uncountered body motion with rocking from side to side and forward to backward. ${ }^{6}$ All of this motion is dampened and balanced in humans, but one cost of the balancing act is repetitive spinal compression by the back muscles during walking in addition to the static requirement of supporting the upper body.

\section{Conclusions}

In summary, the frequency and severity of back pain in modern humans is certainly multifactorial. The only clear evidence that back pain is an especially human problem is the concentration of disk and facet pathophysiology at the points of greatest lordotic curvature because these curves are uniquely human features.

The human lumbar anatomy differs from the anatomy in cercopithecoid monkeys in three major ways: 1) dorsal repositioning of the lumbar transverse processes that obliterates osseoligamentous mechanisms of spinal support; 2) conversion of the iliocostalis lumborum muscle to a highleverage lateral flexor muscle; and 3) conversion of the longissimus lumborum muscle to a high-leverage extensor muscle. The first of these changes is shared with all the hominiform hominoids, the second is shared with the great apes, and the third is a feature mostly in members of the genus Homo.

The effects of these three major types of transformation is an increase in the degree of dynamic, muscularly driven compressive forces on lumbar disks and a greater risk for strains and tears in the muscles of the lumbar region because of their increased leverage. These features are evolutionary innovations that suit the human body plan as well as the evolutionary path and lifestyle of the human lineage. They have supported an upright bipedal species capable of carrying heavy objects and the young across great distances, whether walking or running. In this fashion they have helped our species to more or less conquer the world. Nonetheless, these changes seem to be the principal suspects for any relative increase in the susceptibility to back pain that humans may exhibit relative to the other mammalian species.

\section{References}

1. Deyo RA, Mirza SK, Martin BI: Back pain prevalence and visit rates: estimates from U.S. national surveys, 2002. Spine 31: 2724-2727, 2006

2. Filler AG: Axial Character Seriation in Mammals: An Historical and Morphological Exploration of the Origin, Development, Use and Current Collapse of the Homology Paradigm. PhD Thesis, Department of Anthropology, Harvard University, Cambridge, Massachussetts. Boca Raton, FL: Brown Walker Press, 2007

3. Filler AG: Do You Really Need Back Surgery? A Surgeon's Guide to Neck and Back Pain and How to Choose Your Treatment. New York: Oxford University Press, 2004

4. Filler AG: Evolution of the sacrum in hominoids, in Doty JR, Rengachary SS (eds): Surgical Disorders of the Sacrum. New York: Thieme Medical Publishers, 1993, pp 13-20

5. Filler AG: The Upright Ape: A New Origin of the Species. A Noted Biologist's Groundbreaking Theory of Evolution. Franklin Lakes, NJ: New Page Books, 2007

6. Jenkins FA: Chimpanzee bipedalism: cineradiographic analysis and implications for the evolution of gait. Science 178: 877-879, 1972

7. Kohler M, Moyà-Solà S: Ape-like or hominid-like? The positional behavior of Oreopithecus bambolii reconsidered. Proc Natl Acad Sci U S A 94:11747-11750, 1997

8. MacLatchy L: The oldest ape. Evol Anthropol:90-103, 2004

9. MacLatchy L, Gebo D, Kityo R, Pilbeam D: Postcranial functional morphology of Morotopithecus bishopi, with implications for the evolution of modern ape locomotion. J Hum Evol 39:159-183, 2000 
10. Moyà-Solà S, Kohler M, Alba DM, Casanovas-Vilar I, Galindo J: Pierolapithecus catalaunicus, a new Middle Miocene great ape from Spain. Science 306: 1339-1344, 2004

11. Pilbeam D: The anthropoid postcranial axial skeleton: comments on development, variation, and evolution. J Exp Zoolog B Mol Dev Evol 302:241-267, 2004

12. Roh JS, Teng AL, Yoo JU, Davis J, Furey C, Bohlman H: Degenerative disorders of the lumbar and cervical spine. Orthop Clin North Am 36:255-262, 2005

13. Rook L, Bondioli L, Kohler M, Moyà-Solà S, Macchiarelli R: Oreopithecus was a bipedal ape after all: evidence from the iliac cancellous architecture. Proc Natl Acad Sci U S A 96:87958799,1999

14. Schache AG, Blanch P, Rath D, Wrigley T, Bennell K: Threedimensional angular kinematics of the lumbar spine and pelvis during running. Hum Mov Sci 21:273-293, 2002

15. Stauffer RL, Walker A, Ryder OA, Lyons-Weller M, Hedges SB: Human and ape molecular clocks and constraints on paleontological hypotheses. J Hered 92:469-474, 2001

16. Walker A, Rose MD: Fossil hominoid vertebra from the Miocene of Uganda. Nature 217:980-981, 1968

17. Ward CV: Torso morphology and locomotion in Proconsul nyanzae. Am J Phys Anthropol 92:291-328, 1993
18. Ward CV, Walker A, Teaford MF, Odhiambo I: Partial skeleton of Proconsul nyanzae from Mfangano Island, Kenya. Am J Phys Anthropol 90:77-111, 1993

19. Weinstein JN, Lurie JD, Tosteson TD, Skinner JS, Hanscom B, Toteson AN, et al: Surgical vs nonoperative treatment for lumbar disk herniation: the Spine Patient Outcomes Research Trial (SPORT) observational cohort. JAMA 296:2451-2459, 2006

20. Weinstein JN, Tosteson TD, Lurie JD, Lurie JD, Tosteson ANA, Hanscom B, et al: Surgical vs nonoperative treatment for lumbar disk herniation: the Spine Patient Outcomes Research Trial (SPORT): a randomized trial. JAMA 296:2441-2450, 2006

Manuscript submitted April 23, 2007.

Accepted June 8, 2007.

Portions of this work were supported by the National Institutes of Health Public Health Service Musculoskeletal Biology Training Grant No. 5 T32 GM07117-09 0011

Address reprint requests to: Aaron Filler, M.D., Ph.D., Center for Advanced Spinal Neurosurgery, 2716 Ocean Park Boulevard, Suite 3082, Santa Monica, California 90405. email: afiller @nervemed.com. 